\title{
Kinetic Analysis of Poly(E-caprolactone)/poly(lactic acid) Blends with Low-cost Natural Thermoplastic Starch
}

\author{
Vesna Ocelić Bulatović, ${ }^{1}$ Miće Jakić ${ }^{\star 2}$ and Dajana Kučić Grgić ${ }^{3}$ \\ ${ }^{1}$ Faculty of Metallurgy, University of Zagreb, Sisak, Aleja narodnih heroja 3, HR-44000 Sisak, Croatia \\ ${ }^{2}$ Faculty of Chemistry and Technology, Department of Organic Technology, University of Split, Ruđera Boškovića 35, \\ HR-21000 Split, Croatia \\ ${ }^{3}$ Faculty of Chemical Engineering and Technology, University of Zagreb, Marulicév trg 19, HR-10000 Zagreb, Croatia \\ *Corresponding author: E-mail: mjakic@ktf-split.hr
}

Received: 11-04-2019

\begin{abstract}
Non-isothermal thermogravimetry in an inert atmosphere was used to investigate the thermal stability of poly(e-caprolactone) (PCL), polylactide (PLA), thermoplastic starch (TPS) and their binary (PCL/PLA, PCL/TPS and PLA/TPS) and ternary (PCL/PLA/TPS) blends. All investigated blends were prepared by Brabender kneading chamber. A two-stage degradation pattern is seen in the case of PCL, while PLA exhibits only single stage degradation. On the other hand, the degradation of neat TPS proceeds through three degradation stages. It was found that addition of PLA affects the degradation of PCL/PLA blends indicating PLA's destabilising effect on PCL. TPS addition thermally destabilizes both, PCL and PLA, but notably the PCL sample. Likewise, that addition of TPS thermally destabilized all investigated ternary blends. The obtained data were used for the kinetic analysis of the degradation process. By using the isoconversional Friedman method and the multivariate nonlinear regression method kinetic analysis was performed. Kinetic analysis revealed the complexity of the thermal degradation process for neat samples and all investigated blends. Kinetic parameters (activation energy, pre-exponential factor and kinetic model) for each degradation stage of neat samples and all investigated blends were calculated.
\end{abstract}

Keywords: Kinetic analysis, poly(e-caprolactone), polylactide, Thermogravimetric analysis, thermoplastic starch

\section{Introduction}

In recent decades, the growing environmental awareness has encouraged the development of biodegradable materials from renewable resources to replace conventional non-biodegradable materials in many applications. Therefore, additional approaches, such as using biodegradable plastics, are sought to enforce the reduction of using petroleum-based plastic packaging that ends in landfills, especially in food packaging applications where recycling is difficult or prohibited due to contamination. Similarly to other areas, the plastics industry started looking for alternative sources of raw materials in the last few decades, and considerable interest is shown in natural, renewable solutions. Biopolymers, i.e. polymers produced from renewable feedstock might replace fossil sources and also have considerable environmental benefits like decreased carbon-dioxide emission. ${ }^{1}$ In spite of increasing production capacity, biopolymers are still quite expensive compared to commodity polymers and their properties are also often inferior, or at least do not correspond to the expectation of users. To meet market expectations, the properties of biopolymers must be altered and constantly adapted. Timely, biopolymer modification is at the center of scientific research. In contrast to the development of novel polymeric materials and new polymerization routes, blending is a relatively cheap and fast method to tailor the properties of plastics. The modification of biopolymers by blending with other biopolymers and/or biodegradable materials has many advantages, since it offers an option to adjust properties in a wide range, while legislation also favors completely compostable materials with minimal already mentioned carbon-dioxide emission. Polysaccharides such as starches stand out as a promising replacement of synthetic polymers in plastics industries due to their low cost, non-toxicity, biodegradability and availability. ${ }^{2-4}$ A large number 
of researches are focused on incorporations of starch in the polyester matrix to reduce production costs and maintain the biodegradability. ${ }^{5-7}$ A variety of biodegradable polyesters can be obtained from renewable sources, and of these poly(lactic acid) (PLA) is a material of particular interest due to its exquisite and enviable mechanical properties. ${ }^{5,8}$ Polycaprolactone (PCL) is another polymer which seems to be promising synthetic biodegradable material due to its encouraging properties and its compatibility with many types of polymers. PCL is a good candidate to supplement the shortcomings of PLA. A clear upward trend in PCL and PLA usage in research over the past decade signifies the recognition of these highly versatile resorbable polymers, particularly in the field of biomaterials. ${ }^{9-10}$ PLA/PCL blends offers an interesting and unobtrusive characteristic because of its wide variety of physical property and biodegradability, in which the glassy PLA with high degradation rate shows better tensile strength, while the rubbery PCL with much slower degradation rate shows better toughness. ${ }^{11}$ However, they are extremely costly to be widely used as required by the packaging application. This is the reason why they are blended with lower-cost natural biopolymers such as thermoplastic starch. ${ }^{8,12-14}$ The blending also causes the changes kinetics of decomposition of as individuals' polymers in the blends. The more components in the blend, the process of thermal decomposition of such material is more complex. Because of the thermal degradation of individual polymers in the blends due to their intrinsic chemical reaction processes the investigation of their thermal properties and degradation kinetics of the decomposition is crucial for an accurate prediction of the materials behavior under different working conditions and as well as to optimize the process conditions. ${ }^{15,16}$ In addition, thermal degradation of starch is important to conduct comprehensive studies on their thermal properties and stability of their application in food and pharmaceutical industries and to facilitate their use, since starch undergo thermal processes during their preparation, processing and consumption and on the other hand are poorly researched. ${ }^{17}$ Thermogravimetry (TG) has proved to be reliable method which results can be used for determination of thermal stability of biopolymers and kinetic analysis. ${ }^{15,16}$ On the other hand, the goal of the kinetic analysis is to provide kinetic parameters of the degradation process, i.e. the activation energy $(E)$, the pre-exponential factor $(A)$ and a kinetic model $(f(\alpha))$, the so called "kinetic triplet". Kinetic analysis of the non-isothermal degradation of individual polymer materials and their binary blends has already been studied but from the point of view of ternary blends with starch is a very poor overview of the literature. The thermal degradation of PCL has already been investigated in the literature, ${ }^{18-20}$ but the conclusion is debatable. Persenaire et al. ${ }^{18}$ proposed a two-stage degradation mechanism of random cleavage through cis-elimination and specific chain end scission by unzipping from the hydroxyl end of the polymer chain. Contrary, Aoyagi et al. ${ }^{20}$ proposed a single step degradation mechanism, where the polymer degrades by specific removal of monomer from the end groups. On the other hand, according to the literature, ${ }^{20-23}$ PLA thermal degradation is caused by intramolecular transesterification reactions leading to cyclic oligomers of lactic acid and lactide. Simultaneously, there is a recombination of the cyclic oligomers with linear polyesters through insertion reactions, whereas molecules with longer chains lengths are favoured. Moreover, beside above mentioned, the main decomposition products are acetaldehyde, carbon monoxide, carbon dioxide and methylketene. ${ }^{24}$ The thermo-oxidative degradation of TPS has already been investigated in the literature by several authors. ${ }^{25,26}$ They all concluded that TPS degrades through three or four stages, respectively. Jankovic ${ }^{25}$ determinated that degradation process of the TPS is very complex and proceeds through three main degradation stages with one additional substage attached to the second degradation stage. Futhermore, he concluded that most important degradation stage consist of simultaneously attack of the free radicals on linear and branched molecular forms of the starch. Wahyuningtiyas et al. ${ }^{26}$ utilized TG analysis to obtain the decomposition process mechanism of starch based bioplastic and concluded that decomposition process occurs through four main degradation stages. First stage is the result of the release of moisture or water, while the second one is the main thermal decomposition stage; hence this stage triggers the rapid thermal decomposition with a large mass loss. On the other hand, Guaras et al. ${ }^{27}$ characterized TPS/PCL blends by means of TG analysis under nitrogen atmosphere. Authors confirmed that thermal degradation process of native starch proceeds through three-step reaction; first step corresponds to the water loss, the second between 260 and $330^{\circ} \mathrm{C}$ to starch decomposition and the third between 500 and $600{ }^{\circ} \mathrm{C}$ to the oxidation of partially decomposed starch. In the second step they observed the shoulder on the DTG curve probably due to the degradation events of the main peak through the series of competitive reactions, which includes depolymerization (which can be explained by the chain scission of the glycosidic linkage of polysaccharide). But in the case of TPS they observed a four-step reaction where fourth step corresponds to ethylene glycol degradation.

Altghouh PCL/TPS and PLA/TPS blends have already been investigated in the literature, ${ }^{28-32}$ information about the thermogravimetric and kinetic analysis of the non-isothermal degradation of ternary PCL/PLA/TPS blends couldn't be found. Acordingly, in this work the non-isothermal thermogravimetry in an inert atmosphere and its results were used for determination of thermal stability of PCL, PLA, TPS and their binary (PCL/PLA, PCL/ TPS and PLA/TPS) and ternary (PCL/PLA/TPS) blends. Finnally, by using isoconversional Friedman method $^{33}$ in 
combination with the multivariate non-linear regression method, these results were utilized for determination of the true kinetic triplets of the non-isothermal degradation of neat polymers and their investigated blends.

\section{1. Materials}

The polylactide used in this study was a comercial grade Ingeo $^{\mathrm{TM}}$ Biopolymer4043D supplied by NatureWorks (Minnetonka, MN, USA). Its main properties are a density of $1.24 \mathrm{~g} \mathrm{~cm}^{-3}$ at $25^{\circ} \mathrm{C}$, a glass transition temperature in the $50-70{ }^{\circ} \mathrm{C}$ range, and a melt peak temperature range between $145-160^{\circ} \mathrm{C}$. Regarding to poly(e-caprolactone) (PCL), a commercial grade Polycaprolactone 440744 $\left(\mathrm{MFI}=2.01-4.03 \mathrm{~g} / 10 \mathrm{~min}\right.$ at $\left.160^{\circ} \mathrm{C}\right)$ was supplied by Sigma-Aldrich (Taufkirchen, Germany) in pellet form with a density of $1.145 \mathrm{~g} \mathrm{~cm}^{-3}$. Their average molecular weights are respectively 70000 and $90000 \mathrm{~g} \mathrm{~mol}^{-1}$ by GPC with $M_{w} / M_{n}<2$. The samples were previously dried and used in the experiments in as received pellet form. Wheat varieties "Srpanjka" (harvest 2008) were obtained from Agricultural Institute, Osijek, Croatia. According to the data provided with samples, "Srpanjka" variety contained 68.73 $\%$ d.m. starch, $12.57 \%$ d.m. protein and $12.20 \%$ moisture. Isolation of starch from wheat and characterization of starch was described in research by our colleagues. ${ }^{34}$ Wheat starch (WS) contains $22.49 \pm 2.01$ wt \%. amylose. WS was modified to obtain thermoplastic starch (TPS) by using glycerol. Glycerol was supplied by Gram Mol (Zagreb, Croatia).

\section{2. Sample Preparation}

Preparation of blends, binary and ternary, was carried out in two different stages. Prior to further processing, all materials were dried to avoid moisture, which could affect hydrolysis during manufacturing. PLA were dried at $60{ }^{\circ} \mathrm{C}$ for $24 \mathrm{~h}$, while PCL was dried at $45^{\circ} \mathrm{C}$ for $24 \mathrm{~h}$. The first stages were preparation of thermoplastic starch (TPS). TPS was prepared from a manual mixture of the following components: $70 \mathrm{wt} \%$ native wheat starch and $30 \mathrm{wt} \%$ glycerol. The appropriate amounts of each component were weighed and mechanically pre-mixed in a zipper bag until homogenization. Then, the TPS were extruded in a laboratory single-screw extruder (Model 19/20DN; Brabender $\mathrm{GmbH}$, Germany). The extrusion parameters were as follows: screw 1: 1 and die $4 \mathrm{~mm}$. A rotating speed of 40 rpm was used with a temperature profile of $130^{\circ} \mathrm{C}$ (ejection zone), $100{ }^{\circ} \mathrm{C}$ (compression zone), and $100{ }^{\circ} \mathrm{C}$ (feeding hopper) and with dosing speed of $15 \mathrm{rpm}$. These conditions provide good processing in terms of viscosity and avoid thermal degradation. After extrusion the samples were air-dried overnight and then stored in sealed plastic bags at room temperature until further analysis. The next stage was prepared binary and ternary blends using a Brabender kneading chamber. The components were put in the chamber preheated up to $170{ }^{\circ} \mathrm{C}$ with a rotor speed of $50 \mathrm{rpm}$, and kneaded for $6 \mathrm{~min}$. After homogenization the blends was pelletized and subsequently moulded in laboratory hydraulic press Fontune, Holland (SRB 140, EC $320 \times 320 \mathrm{NB}$ ) at $180{ }^{\circ} \mathrm{C}$ under a pressure of 25 bar for 5 min, and then kept at room temperature. Throughout this paper the designation for example PCL30/PLA70 refers to 30 wt \% of PCL and 70 wt \% of PLA in the blend. After preparation of the binary PCL/PLA blends, TPS was then blended with blends in a weight composition of $30 \mathrm{wt} \%$. The amount of TPS in all ternary blends was maintained constant.

\section{3. Thermogravimetric Analysis}

The thermal degradation of the PCL/PLA/TPS blends (sample mass approximately $10 \mathrm{mg}$ ) was performed by using PerkinElmer Pyris 1 TGA thermobalance at the heating rates of $2.5,5,10$ and $20^{\circ} \mathrm{C} \mathrm{m^{-1 }}$ in a temperature range $50-550{ }^{\circ} \mathrm{C}$ under a steady flow of nitrogen $\left(20 \mathrm{~cm}^{3}\right.$ $\left.\mathrm{min}^{-1}\right)$. In order to estimate the thermal stability of the investigated polymers and their blends different criteria was used. From thermogravimetric curves (TG) (mass versus degradation temperature), and corresponding derivative thermogravimetric curves (DTG) (mass loss rate versus temperature) the following characteristics were determined: the onset temperature $\left(T_{\text {onset }}\right)$, the temperature at $5 \%$ mass loss $\left(T_{5 \%}\right)$, the temperature at the maximum degradation rate $\left(T_{\max }\right)$, the maximum degradation rate $\left(R_{\max }\right)$, the final mass $\left(m_{\mathrm{f}}\right)$ and the mass loss $(\Delta m)$ for the corresponding degradation steps.

\section{4. Kinetic Analysis}

The non-isothermal TG data can be used for the kinetic analysis of the investigated process. Kinetic analysis of the solid-state reactions that are ruled by a single process is based on Eq. (1):

$$
\frac{\mathrm{d} \alpha}{\mathrm{dt}} \cong \beta \frac{\mathrm{d} \alpha}{\mathrm{dT}}=\mathrm{A} \cdot \exp \left(-\frac{\mathrm{E}}{\mathrm{RT}}\right) \cdot \mathrm{f}(\alpha)
$$

where $\alpha$ is the degree of conversion, $\beta$ is the linear heating rate $\left({ }^{\circ} \mathrm{C} \mathrm{min}^{-1}\right), T$ is the absolute temperature $(\mathrm{K}), R$ is the general gas constant $\left(\mathrm{J} \mathrm{mol}^{-1} \mathrm{~K}^{-1}\right)$ and $t$ is the time (min). It is suggested that prior to any kinetic analysis one should investigate the complexity of the process by determining the dependence of $\mathrm{E}$ on a by isoconversional methods. Based on the recommendations of ICTAC Kinetics Committee for performing kinetic computations on thermal analysis data and other reliable literature, ${ }^{35-38}$ the principle, basic equations of the solid-state reactions and isoconversional Friedman method and the experimental procedure of kinetic analysis were described in detail in already 
published papers. ${ }^{39-41}$ The Netzsch Thermokinetic 3.1 software ${ }^{42}$ was utilized for determination of the true kinetic triplets of the non-isothermal degradation of neat polymers and their investigated blends.

\section{Results and Discussion}

\section{1. Thermogravimetric Analysis}

In Fig. 1 TG and corresponding DTG curves of PCL/ PLA blends obtained at $2.5^{\circ} \mathrm{C} \mathrm{min}{ }^{-1}$ are shown and from them derived data (Table 1) were used to obtain information of the thermal stabilty of PCL and PLA, respectively. Neat PCL showed a two-stage degradation pattern, where its degradation starts at $374{ }^{\circ} \mathrm{C}\left(T_{\text {onset } 1}\right)$ and ends at $475^{\circ} \mathrm{C}$ with a peak temperature at $383{ }^{\circ} \mathrm{C}\left(T_{\max 1}\right)$ and $431{ }^{\circ} \mathrm{C}$ $\left(T_{\max 2}\right)$. Thermal degradation of PCL proceeds almoust totally without residue which is supported by the fact that total weight loss through two degradation stages is $99.0 \%$. Contrary, thermal degradation of the neat PLA is characterized by only a single stage degradation stage that unrolls between $319^{\circ} \mathrm{C}\left(T_{\text {onset }}\right)$ and $400{ }^{\circ} \mathrm{C}$ confirming its inferior thermal stability to PCL. The peak temperature is observed at $339^{\circ} \mathrm{C}$ and as in the case of PCL the total weight loss is found to be $99.2 \%$.

As predicted, a two-stage degradation pattern can be seen in the case of the PCL/PLA blends 50/50 and $30 / 70$, while for blend $70 / 30$ degradation proceeds through three stages. From the dependence of the characteristics of TG and DTG curves on the blend composition (Table 1) it can be concluded that the degradation of PCL/PLA blends is affected by addition of PLA and con- sequently degradation process starts at lower temperatures. This could be an indication of PLA destabilising effect on PCL. The mass loss in the first degradation stage
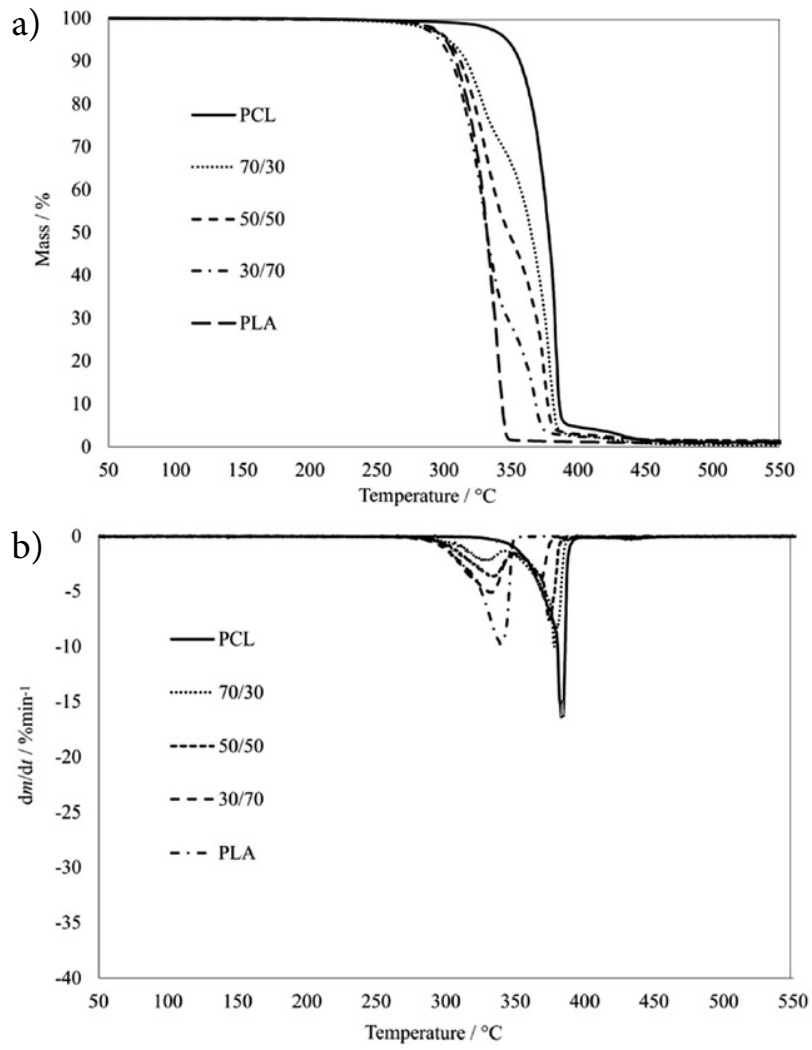

Fig. 1. TG (a) and DTG (b) curves of the thermal degradation of the PCL/PLA blends at the heating rate of $2.5^{\circ} \mathrm{C} \mathrm{min}-1$.

Table 1. The characteristics of thermal degradation curves of PCL/PLA blends (heating rate $2.5^{\circ} \mathrm{C} \mathrm{min}^{-1}$ )

\begin{tabular}{|c|c|c|c|c|c|c|}
\hline PCL/PLA & $T_{5 \%}\left({ }^{\circ} \mathrm{C}\right)$ & $T_{\text {onset }}\left({ }^{\circ} \mathrm{C}\right)$ & $T_{\max }\left({ }^{\circ} \mathrm{C}\right)$ & $R_{\max }\left(\% \mathrm{~min}^{-1}\right)$ & $\Delta m(\%)$ & $m_{\mathrm{f}}(\%)$ \\
\hline \multicolumn{7}{|c|}{ First stage } \\
\hline $100 / 0$ & 347 & 374 & 383 & 16.4 & 95.5 & 4.5 \\
\hline $70 / 30$ & 303 & 306 & 330 & 2.2 & 29.4 & 70.6 \\
\hline $50 / 50$ & 303 & 310 & 334 & 3.6 & 50.7 & 49.3 \\
\hline $30 / 70$ & 296 & 307 & 332 & 5.1 & 71.3 & 28.7 \\
\hline $0 / 100$ & 301 & 319 & 339 & 9.7 & 99.2 & 0.8 \\
\hline \multicolumn{7}{|c|}{ Second stage } \\
\hline $100 / 0$ & - & 422 & 431 & 0.2 & 3.5 & 1.0 \\
\hline $70 / 30$ & - & 365 & 378 & 10.1 & 67,9 & 2.7 \\
\hline $50 / 50$ & - & 366 & 374 & 7.6 & 47.9 & 1.4 \\
\hline $30 / 70$ & - & 361 & 368 & 4.1 & 27.3 & 1.4 \\
\hline $0 / 100$ & - & - & - & - & - & - \\
\hline \multicolumn{7}{|c|}{ Third stage } \\
\hline $100 / 0$ & - & - & - & - & - & - \\
\hline $70 / 30$ & & 411 & 425 & 0.1 & 1,6 & 1.1 \\
\hline $50 / 50$ & - & - & - & - & - & - \\
\hline $30 / 70$ & - & - & - & - & - & - \\
\hline $0 / 100$ & - & - & - & - & - & - \\
\hline
\end{tabular}


increased, while mass loss in the second degradation stage decreased linearly as the PLA content increased in the blend. The final mass at the end of the degradation is around $1 \%$ and practically independent on blend composition. Unexpectedly, PCL/PLA 30/70 blend showed the worst thermal stability, even than the neat PLA (Fig. 1, Table 1).

The TG/DTG curves of PCL/TPS and PLA/TPS blends obtained at $2.5{ }^{\circ} \mathrm{C} \mathrm{min}-1$ are shown in Fig. 2. Derived data are tabulated in Table 2 and used to indicate the effect of TPS addition on the degradation process of PCL and PLA, respectively. The PCL/TPS blend showed a three-stage degradation pattern while PLA/TPS blend degrades through two-stage degradation process. However, the degradation of neat TPS proceeds through three degradation stages starting from $91{ }^{\circ} \mathrm{C}\left(T_{\text {onset } 1}\right)$ to $500{ }^{\circ} \mathrm{C}$ with a peak temperature at $128^{\circ} \mathrm{C}\left(T_{\max 1}\right), 271^{\circ} \mathrm{C}\left(T_{\max 2}\right)$ and $301{ }^{\circ} \mathrm{C}\left(T_{\max 3}\right)$ with total weight loss of $88.5 \%$. From data tabulated in Table 1 and 2 it can be seen that addition of TPS affects the degradation of neat PCL and PLA and consequently their degradation starts at lower temperatures. Unexpectedly, investigated PLA/TPS blend if compared with PCL/TPS blend showed superior thermal stability. Finnally, from Fig. 2 it can be concluded that TPS addition thermally destabilizes both, PCL and PLA, but notably the PCL sample.

The resulting TG/DTG curves of the non-isothermal thermogravimetry degradation of investigated ternary PCL/PLA/TPS blends obtained at $2.5^{\circ} \mathrm{C} \mathrm{min}-1$ are showed in Fig. 3. Obtained data (Table 3) were used to evaluate the effect of TPS addition on the degradation pattern of PCL/ PLA blends.

All investigated PCL/PLA/TPS blends revealed a four-stage degradation pattern, except the blend $30 / 70 / 30$ which degradation proceeds through three stages. If temperature areas of thermal degradation of neat polymers are compared it can be concluded that
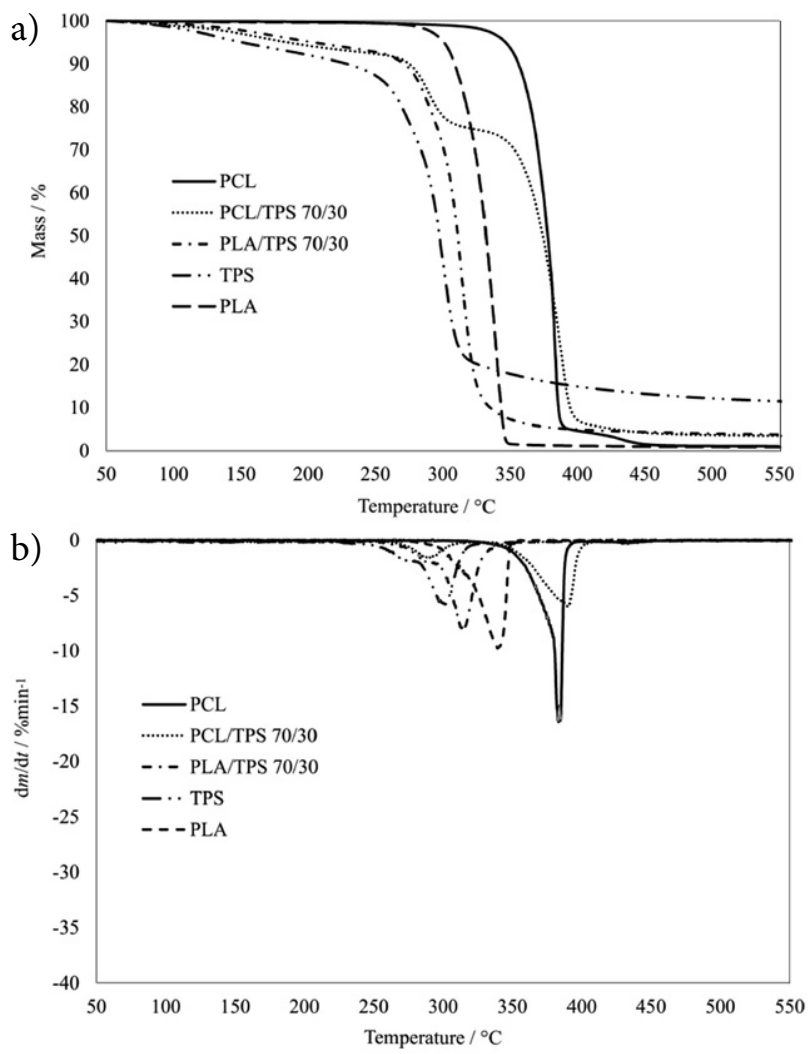

Fig. 2. TG (a) and DTG (b) curves of the thermal degradation of the $\mathrm{PCL} / \mathrm{TPS}$ and PLA/TPS blends at the heating rate of $2.5^{\circ} \mathrm{C} \mathrm{min}{ }^{-1}$.

first and second degradation stages correspond to thermal degradation of TPS, while the third and fourth ones correspond to thermal degradation of PLA and PCL (Fig. 3), respectively.

It is evident, as well in the case of above mentioned blends, that addition of TPS thermally destabilized all investigated samples. However, addition of PLA hasn't affected the thermal stability of investigated blends (Table

Table 2. The characteristics of thermal degradation curves of PCL/TPS and PLA/TPS blends (heating rate $2.5^{\circ} \mathrm{C} \mathrm{min}{ }^{-1}$ )

\begin{tabular}{|c|c|c|c|c|c|c|}
\hline Sample & $T_{5 \%}\left({ }^{\circ} \mathrm{C}\right)$ & $T_{\text {onset }}\left({ }^{\circ} \mathrm{C}\right)$ & $T_{\max }\left({ }^{\circ} \mathrm{C}\right)$ & $R_{\max }\left(\% \min ^{-1}\right)$ & $\Delta m(\%)$ & $m_{\mathrm{f}}(\%)$ \\
\hline \multicolumn{7}{|c|}{ First stage } \\
\hline PCL/TPS & 185 & 105 & 157 & 0.2 & 7.7 & 92.3 \\
\hline PLA/TPS & 204 & 115 & 174 & 0.1 & 6.3 & 93.7 \\
\hline TPS & 151 & 91 & 128 & 0.2 & 8.0 & 92.0 \\
\hline \multicolumn{7}{|c|}{ Second stage } \\
\hline PCL/TPS & - & 276 & 289 & 1.6 & 17.4 & 74.9 \\
\hline PLA/TPS & - & 298 & 315 & 8.0 & 89.9 & 3.8 \\
\hline TPS & - & 256 & 271 & 1.8 & 16.3 & 75.7 \\
\hline \multicolumn{7}{|c|}{ Third stage } \\
\hline PCL/TPS & - & 364 & 390 & 6.1 & 71.4 & 3.5 \\
\hline PLA/TPS & - & - & - & - & - & - \\
\hline TPS & - & 292 & 301 & 5.8 & 64.2 & 11.5 \\
\hline
\end{tabular}


3). Contrary to the PCL/PLA blends, the blend with increased PLA content showed better thermal stability. This fact is consistent with above mentioned conclusion
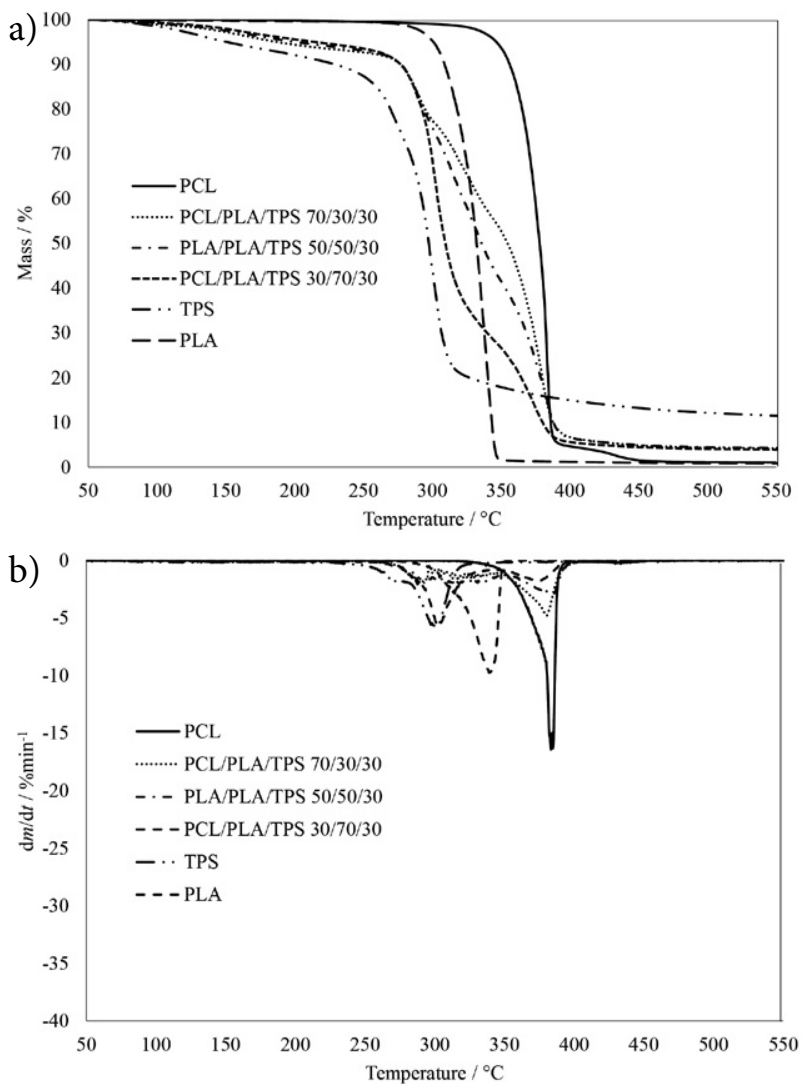

Fig. 3. TG (a) and DTG (b) curves of the thermal degradation of the PCL/PLA/TPS blends at the heating rate of $2.5^{\circ} \mathrm{Cmin}^{-1}$. that, if compared with PCL/TPS blend, investigated PLA/ TPS blend showed superior thermal stability.

The TG/DTG curves of PCL, PLA, TPS and their binary (PCL/PLA, PCL/TPS and PLA/TPS) and ternary (PCL/PLA/TPS) blends gained at higher heating rates (5, 10 and $20^{\circ} \mathrm{C} \mathrm{m^{-1 }}$ ) are similar by pattern to those at 2.5 ${ }^{\circ} \mathrm{C} \mathrm{min}^{-1}$ and shifted to higher temperatures and higher maximum rates od degradation, respectively.

\section{2. Kinetic Analysis}

In order to obtain the valuable information about the degradation kinetics of PCL, PLA and their blends with TPS, raw data extracted from non-isothermal thermogravimetric analysis were utilized. Firstly, by using classical linear "model-free" Friedman kinetic method, the dependence of the activation energy $(E)$ in function of the conversion degree $(\alpha)$ was evaluated. From Fig. 4 it can be undoubtedly concluded that in a whole conversion range $E$ depends on $\alpha$ for all investigated samples, indicating complex multi-step degradation mechanism. Therefore, it is necessary to carry out a multi-step kinetic analysis which can be achieved by using the model fitting multivariate non-linear regression method. ${ }^{37,38}$ This will provide a true kinetic triplet for each reaction step. Apparent activation energy of neat PCL sample showed two or more inflection points or maximums (Fig. 4) indicating that degradation takes place at least in two main steps.

This fact can be confirmed by reviewing DTG curves (Fig. 1). Sivalingam et al. ${ }^{19}$ investigated kinetics of thermal degradation of PCL under non-isothermal and isothermal heating by TG in a nitrogen environment. $\mathrm{Au}-$

Table 3. The characteristics of thermal degradation curves of PCL/PLA/TPS blends (heating rate $2.5^{\circ} \mathrm{C} \mathrm{min}{ }^{-1}$ )

\begin{tabular}{|c|c|c|c|c|c|c|}
\hline Sample & $T_{5 \%}\left({ }^{\circ} \mathrm{C}\right)$ & $T_{\text {onset }}\left({ }^{\circ} \mathrm{C}\right)$ & $T_{\max }\left({ }^{\circ} \mathrm{C}\right)$ & $R_{\max }\left(\% \min ^{-1}\right)$ & $\Delta m(\%)$ & $m_{\mathrm{f}}(\%)$ \\
\hline \multicolumn{7}{|c|}{ First stage } \\
\hline $70 / 30 / 30$ & & 113 & $169^{\circ}$ & 0.2 & 6.9 & 93.1 \\
\hline $50 / 50 / 30$ & & 101 & 170 & 0.2 & 6.0 & 94.0 \\
\hline $30 / 70 / 30$ & & 110 & 165 & 0.1 & 4.9 & 95.1 \\
\hline \multicolumn{7}{|c|}{ Second stage } \\
\hline $70 / 30 / 30$ & - & 277 & 291 & 1.8 & 16.6 & 76.4 \\
\hline $50 / 50 / 30$ & - & 276 & 292 & 2.0 & 19.0 & 75.0 \\
\hline $30 / 70 / 30$ & - & 288 & 302 & 1.7 & 66.2 & 28.9 \\
\hline \multicolumn{7}{|c|}{ Third stage } \\
\hline $70 / 30 / 30$ & - & 310 & 316 & 1.6 & 20.6 & 55.8 \\
\hline $50 / 50 / 30$ & - & 307 & 315 & 2.0 & 33.9 & 41.1 \\
\hline $30 / 70 / 30$ & - & 360 & 375 & 5.7 & 25.0 & 3.9 \\
\hline \multicolumn{7}{|c|}{ Fourth stage } \\
\hline $70 / 30 / 30$ & - & 364 & 380 & 4.8 & 51.6 & 4.2 \\
\hline $50 / 50 / 30$ & - & 367 & 384 & 2.9 & 36.8 & 4.3 \\
\hline $30 / 70 / 30$ & - & - & - & - & - & - \\
\hline
\end{tabular}


thors suggested that PCL undergoes two degradation stages by a parallel mechanism including random chain scission and specific chain end scission for non-isothermal heating. Hence, with detailed insight into apparent activation energy of degradation of PCL calculated by Friedman method three areas with different $E$ values can be observed.

On the other hand, PLA exhibits three stage degradation mechanisms. Badia et al. ${ }^{23}$ investigated thermal decomposition kinetics of PLA in argon atmosphere. Authors concluded that PLA degrades under only one degradation stage which can be described by two competitive different decomposition models: on the one hand, a Nucleation model (A2), which gives importance to specific decomposition sites; and on the other hand, a Reaction Contracting model (R3), which represents a particles release generalized on the whole polymer surface. Since the main mass loss decomposition process occured in the narrow conversion range (0.2-0.7), authors focused on that range. The Netzsch Thermokinetic 3.1 software allows calculation in the much wider conversion range; therefore, in this work kinetic analysis was done in a whole conversion range (0.0-1.0).

Accordingly, PLA sample showed three different areas of apparent activation energy. As expected, PCL/PLA blends showed even four different areas of apparent activation energy, except for PCL/PLA 30/70 blend which showed five different areas.

Kinetic model of thermal degradation of investigated samples can be determined by the multivariate non-linear regression analysis incorporated in Netzsch Thermokinetic 3.1 software. This analysis was based on the results of the activation energy as well as on the shape and slope of experimental points and isoconversional lines from Friedman plots. More details can be found in our previous works. ${ }^{39-41}$ F-test, correlation coefficient and especially the similarity of obtained $E$ values with those calculated by FR method enabled to find the best fit of the model function that reasonably describes a kinetic model of degradation. Apparent activation energy values obtained by the FR method for each degradation stage, as well as the results of calculations for the most probable kinetic models on the basis of F-test and correlation coefficient are summarized in Table 4. Fig. 5a shows the comparison of experimental data (points) and best fitted kinetic models (solid lines) calculated from multivariate non-linear regression for the PCL sample.

Three-stage degradation mechanism, in this case with consecutive reactions $\mathrm{A} \rightarrow \mathrm{B} \rightarrow \mathrm{C} \rightarrow \mathrm{D}$, proved to be appropiate for fitting the experimental data and the as-
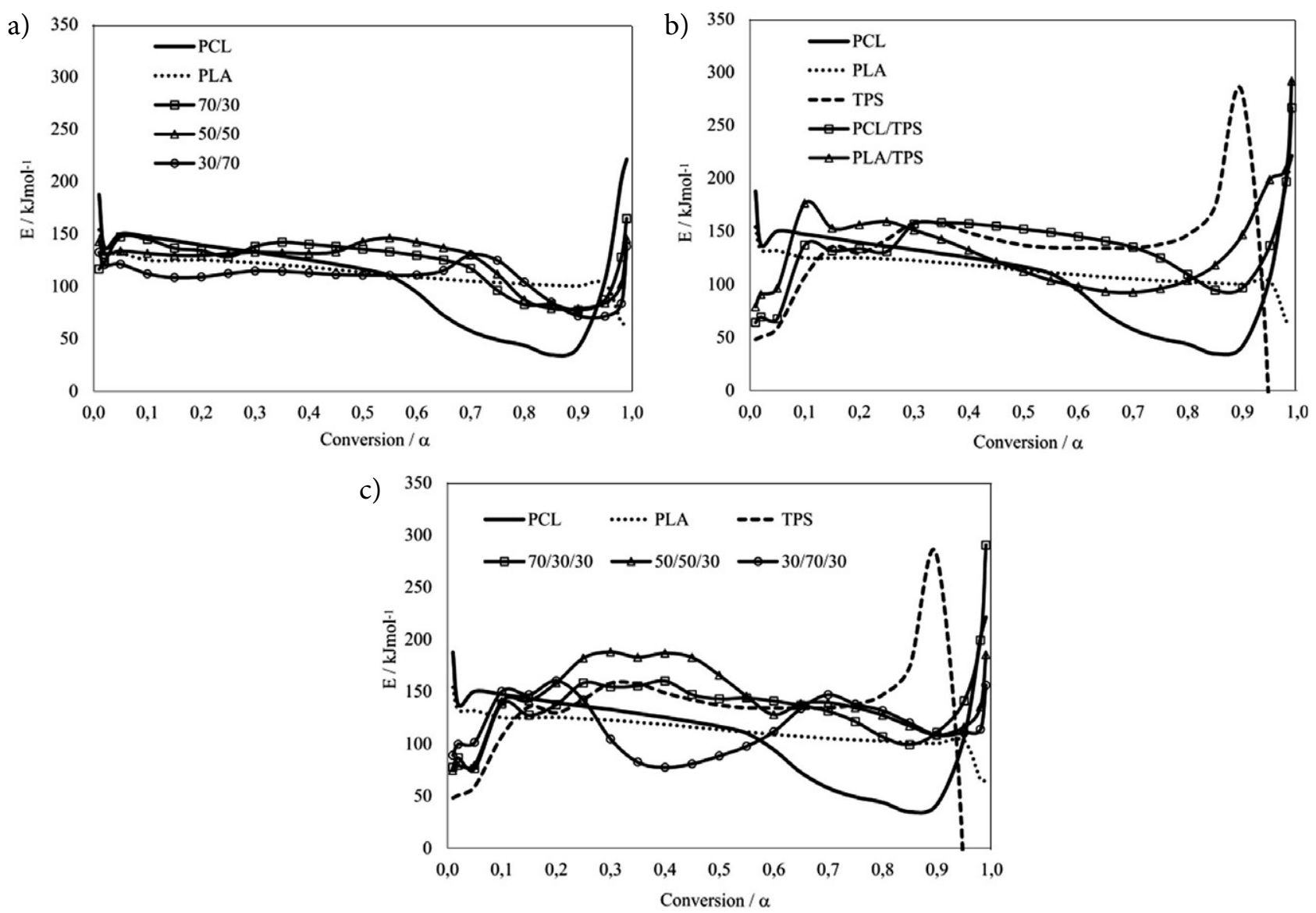

Fig. 4. Dependence of $E$ on $a$ determined by Friedman method of PCL/PLA (a), PCL/TPS and PLA/TPS (b) and PCL/PLA/TPS (c) blends. 
Table 4. The most probable kinetic models of thermal degradation of PCL/PLA blends according to F-test and correlation coefficient obtained by using multivariate non-linear regression analysis

\begin{tabular}{|c|c|c|c|c|c|c|}
\hline \multirow{2}{*}{ Stage of reaction } & \multirow{2}{*}{ Parameter } & \multicolumn{5}{|c|}{ PCL/PLA } \\
\hline & & $100 / 0$ & $70 / 30$ & $50 / 50$ & $30 / 70$ & $0 / 100$ \\
\hline \multirow{4}{*}{ Stage I } & $\mathrm{E}_{1} / \mathrm{kJmol}^{-1}$ & 148.7 & 122.6 & 130.0 & 128.1 & 154.0 \\
\hline & $\log A_{1}$ & 8.6 & 7.5 & 8.8 & 8.3 & 10.1 \\
\hline & $\mathrm{n}$ & 0.4 & 1.0 & 1.3 & 0.7 & 0.4 \\
\hline & Model & $\mathrm{Cn}$ & $\mathrm{Cn}$ & An & $\mathrm{Cn}$ & $\mathrm{Cn}$ \\
\hline \multirow[t]{2}{*}{ Friedman } & $\mathrm{kJmol}^{-1}$ & $128.8-150.0$ & $116.4-147.1$ & $130.0-142.5$ & $108.3-132.5$ & $125.1-153.9$ \\
\hline & $\mathrm{E}_{2} / \mathrm{kJ} \mathrm{mol}^{-1}$ & 73.9 .0 & 139.9 & 131.3 & 104.6 & 112.0 \\
\hline \multirow[t]{3}{*}{ Stage II } & $\log A_{2}$ & 3.0 & 8.3 & 8.9 & 6.3 & 7.7 \\
\hline & $\mathrm{n}$ & 5.1 & 3.8 & 0.9 & 0.4 & 4.3 \\
\hline & Model & An & An & An & $\mathrm{Cn}$ & An \\
\hline \multirow[t]{2}{*}{ Friedman } & $\mathrm{kJmol}^{-1}$ & $34.4-121.0$ & $117.0-140.1$ & $129.3-132.1$ & $110.3-115.1$ & $101.1-120.4$ \\
\hline & $\mathrm{E}_{3} / \mathrm{kJmol}^{-1}$ & 219.0 & 87.2 & 132.1 & 131.5 & 65.1 \\
\hline \multirow[t]{3}{*}{ Stage III } & $\log A_{3}$ & 13.6 & 4.5 & 7.8 & 8.1 & 2.8 \\
\hline & $\mathrm{n}$ & 1.1 & 0.3 & 0.2 & 0.1 & 5.0 \\
\hline & Model & Fn & $\mathrm{Cn}$ & $\mathrm{Cn}$ & $\mathrm{Cn}$ & An \\
\hline \multirow[t]{2}{*}{ Friedman } & $\mathrm{kJmol}^{-1}$ & $106.1-221.2$ & $77.2-96.1$ & $132.8-146.1$ & $104.0-129.9$ & $64.5-100.3$ \\
\hline & $\mathrm{E}_{4} / \mathrm{kJmol}^{-1}$ & - & 127.1 & 139.5 & 81.2 & - \\
\hline \multirow[t]{3}{*}{ Stage IV } & $\log \mathrm{A}_{4}$ & - & 7.8 & 9.6 & 4.8 & - \\
\hline & $\mathrm{n}$ & - & 1.7 & 1.8 & 2.0 & - \\
\hline & Model & - & Fn & Fn & An & - \\
\hline \multirow[t]{2}{*}{ Friedman } & $\mathrm{kJmol}^{-1}$ & - & $127.8-164.8$ & $87.3-145.1$ & $71.7-84.9$ & - \\
\hline & $\mathrm{E}_{5} / \mathrm{kJmol}^{-1}$ & - & - & - & 131.6 & - \\
\hline \multirow[t]{3}{*}{ Stage V } & $\log A_{5}$ & - & - & - & 8.2 & - \\
\hline & $\mathrm{n}$ & - & - & - & 0.9 & - \\
\hline & Model & - & - & - & Fn & - \\
\hline Friedman & $\mathrm{kJmol}^{-1}$ & - & - & - & $83.5-137.9$ & - \\
\hline
\end{tabular}

sumed kinetic models for PCL sample. The first stage of thermal degradation of PCL can be described by the reaction of $\mathrm{n}$-th order with autocatalysis (Cn). This is partially in accordance with the work of Sivalingam et al. ${ }^{19}$ where thermal degradation of PCL is described by a parallel mechanism including random chain scission and specific chain end scission. The second stage of thermal degradation of PCL sample may be described by the reaction of An kinetic model with a lower $E$ value. This is not in accordance with the literature and ultimately with the features of fast autocatalytic random chain scission reaction. However, this divergence may be attributed to different sample preparation conditions, i.e. it may suffer thermal degradation when kept at temperatures higher than its melting point. In the final third stage, thermal degradation of investigated PCL sample can be described by the reaction of nth order (Fn). Considering the previous stages, this stage showed the highest apparent activation energy values which could be accounted by the higher collision frequencies at the higher degradation temperatures. ${ }^{43}$

Likewise, three-stage degradation mechanism (A $\rightarrow \mathrm{B} \rightarrow \mathrm{C} \rightarrow \mathrm{D}$ ) proved to be appropiate for fitting the experimental data and the assumed kinetic models for
PLA sample as well (Fig. 5b). One again, the $E$ obtained by Friedman method indicated that the first stage of degradation of PLA also might occur by the Cn kinetic model.

Although this conclusion is contrary to the literature data, in our opinion, Cn kinetic model reasonably describes first stage of the thermal degradation of PLA, both mathematically and functionally. The second stage of thermal degradation of PLA sample was also described by the reaction of An kinetic model, with the apparent activation energy which is lower than the one in the first stage. This is in accordance with the work of Badia et al. ${ }^{23}$ where degradation of PLA was described by nucleation model (A2). Authors focused on the narrow conversion range $(0.2-$ 0.7), which corresponds to the second stage of the degradation of PLA sample in this work. On the other hand, the final third stage of degradation of PLA sample occurs by the An reaction type. This stage can be considered as the continuation of the degradation process from second stage of degradation of PLA sample. This fact would support the assumption that thermal degradation of PLA takes place through a mechanism of nucleation and growth of nuclei by a diffusion-controlled process which is considered to be 

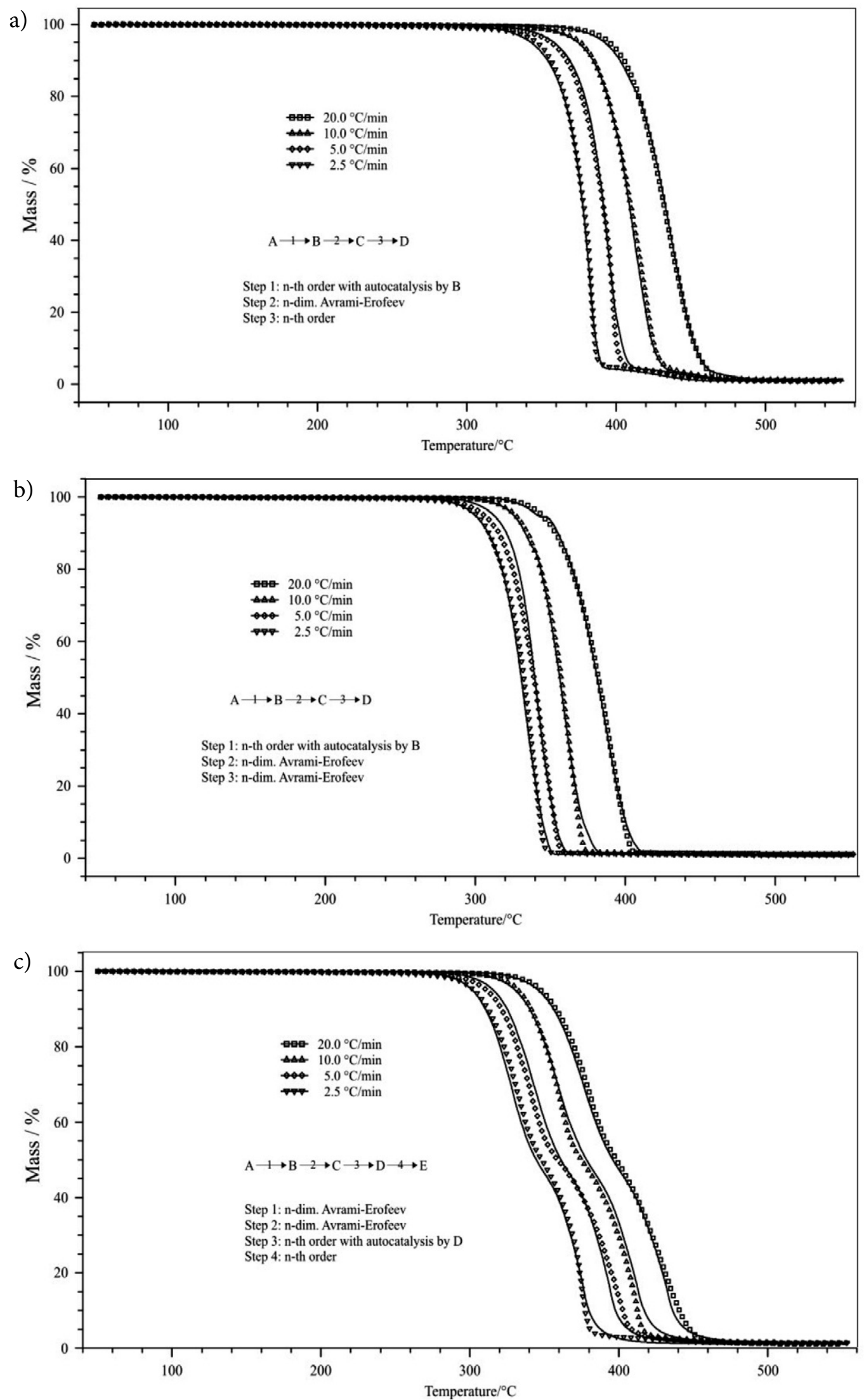

Fig. 5. Comparison of experimental data (points) and best fitted kinetic models (solid lines) calculated from multivariate nonlinear regression method for the PCL (a), PLA (b) and PCL/PLA (50/50) (c). 
the best suited kinetic model for description of thermal degradation of PLA. ${ }^{23}$

However, a four-stage degradation mechanism ( $\mathrm{A} \rightarrow$ $\mathrm{B} \rightarrow \mathrm{C} \rightarrow \mathrm{D} \rightarrow \mathrm{E}$ ) is seen in the case of the PCL/PLA blends $70 / 30$ and 50/50 (Fig. 5c), while for PCL/PLA 30/70 blend degradation proceeds through five stages. These conclusions can be verified by the high correlation coefficient above 0.999 . In order to eliminate complications and simplify discussion, it can be summarized that all stages of degradation for all PCL/PLA blends can be described alternately with either $\mathrm{Cn}$ or An kinetic model (Table 4). These results clearly indicate that the addition of PLA has negligible effect on the degradation kinetics of PCL and vice versa. These models belong to the same accelerating reaction type ${ }^{42}$ and by this work proved to be the main kinetic models for characterization of the degradation process of the PCL/PLA blends. As mentioned before, contrary to the neat samples (PCL and PLA), PCL/PLA blends showed two more degradation stages, a fourth stage in the case of the blends 70/30 and 50/50 and fifth stage for blend 30/70. Finnally, Fn model denotes the end of the investigated degradation process, as in the case of neat PCL.

Based on the result of TG analysis (section 3.1.) it was concluded that degradation of natural biopolymer TPS takes place at least in three main steps. Hence, Fig. 4(b) clearly indicates four different areas of apparent activation energy for TPS sample. Contrary to other samples, in case of TPS the remaining mass of the sample depends on the heating rate (Fig. 6(a)) indicating a multi-step branched reaction path. ${ }^{42}$

Therefore, the best fit for TPS sample was obtained for the four-stage degradation mechanisms with branching reaction (Table 5). The apparent $E$ of the first stage of thermal degradation of TPS obtained by Friedman method indicated that this stage might occur by diffusion mechanism (three-dimensional diffusion GinstlingBrounstein type) (D4). At the first stage, at low conversion degrees on Friedman plot the experimental points showed a lower slope than the isoconversional lines, ${ }^{39-42}$ which is in accordance with results of nonlinear regression. At the beginning of thermal degradation, a solid or a highly viscous melt system occurs and the mass transfer processes became rate determining. Hence, the decomposition products must diffuse to the surface to be evaporated, and diffusion of the volatile products toward the surface is the rate-controlling process in the first stage. ${ }^{44}$ This is in accordance with the literature ${ }^{27}$ and ultimately proves that the first stage consists of the release of moisture or water (rate-controlling process) from the TPS melt. The second stage of thermal degradation of TPS sample may be described by the $\mathrm{Cn}$ kinetic model with a higher $E$ value. The second one is the main thermal decomposition stage and this stage triggers the rapid thermal decomposition with a large mass loss. ${ }^{26}$ The second stage continues through two competitive processes, which represent the third and fourth stages. This is in accordance with the work of the
Guaras et al. ${ }^{27}$ where the main degradation process proceeded through the series of competitive reactions, which includes depolymerization (by the chain scission of the glycosidic linkage of polysaccharide). In this case the chain scission is described with An kinetic model through the third and fourth stage of TPS degradation.

Contrary, in case of the PLA/TPS and PCL/TPS (Fig. $6 \mathrm{~b})$ blends the remaining mass of the samples does not depend on the heating rate indicating a multi-step unbranched reactions with a four-stage and five-stage degradation mechanism, respectively. Likewise, the apparent $E$ of thermal degradation of investigated PCL/TPS and PLA/ TPS blends in the first stage are quite lower than in the case of the neat polymers (Table 4) and reveal diffusion character (D4) (Table 5). These results prove that the addition of TPS influences the thermal degradation and kinetics of PCL and PLA, respectively. However, the folowing stages of degradation for PCL/TPS and PLA/TPS blends can be described with either An or Cn kinetic model which is more-less consistent with the degradation mechanisms of the neat polymers (Table 4).

It can be concluded that TPS delays chain scission of PCL described with An kinetic model to higher conversions compared to neat PCL. Likewise, TPS addition also affects the PLA sample degradation pattern by shifting its nucleation process to higher conversion range.

Taking into account the above PLA/TPS and PCL/ TPS blends could practically be described with three and four-stage process.

One of the main objectives of this work was to study non-isothermal degradation mechanisms and kinetics of the ternary PCL/PLA/TPS blends. The dependences of $E$ on $\alpha$ evaluated at whole conversion range by means of FR method are shown in Fig. 4(c). The presence of four or more inflection points or maximums for investigated samples (Fig. 4(c)) indicates that degradation takes place at least in four main steps, which is consistent with TG and DTG results (Fig. 3). The remaining mass of all investigated ternary PCL/PLA/TPS blends does not depend on the heating rate indicating multi-step unbranched reactions, ${ }^{42}$ in this case five-stage degradation mechanisms with consecutive reactions $\mathrm{A} \rightarrow \mathrm{B} \rightarrow \mathrm{C} \rightarrow \mathrm{D} \rightarrow \mathrm{E} \rightarrow \mathrm{F}$ (Fig. 6c and Table 6). The apparent activation energy of the first stage of thermal degradation of all investigated PCL/PLA/ TPS samples reveals diffusion character (D4). Evidently, these results prove that the addition of TPS influences the thermal degradation and kinetics of PCL/PLA blends, at least in the first stage. However, the following stages of degradation for PCL/PLA/TPS blends can be described with either An or Cn kinetic model which is more-less consistent with the degradation mechanisms of the PCL/ PLA blends (Table 4). However, one can notice that the third stage of degradation of PCL/PLA/TPS blend 30/70/30 was described by another (different) kinetic model known as expanded Prout-Tompkins equation (Bna). This shouldn't be suprissing since kinetic model 

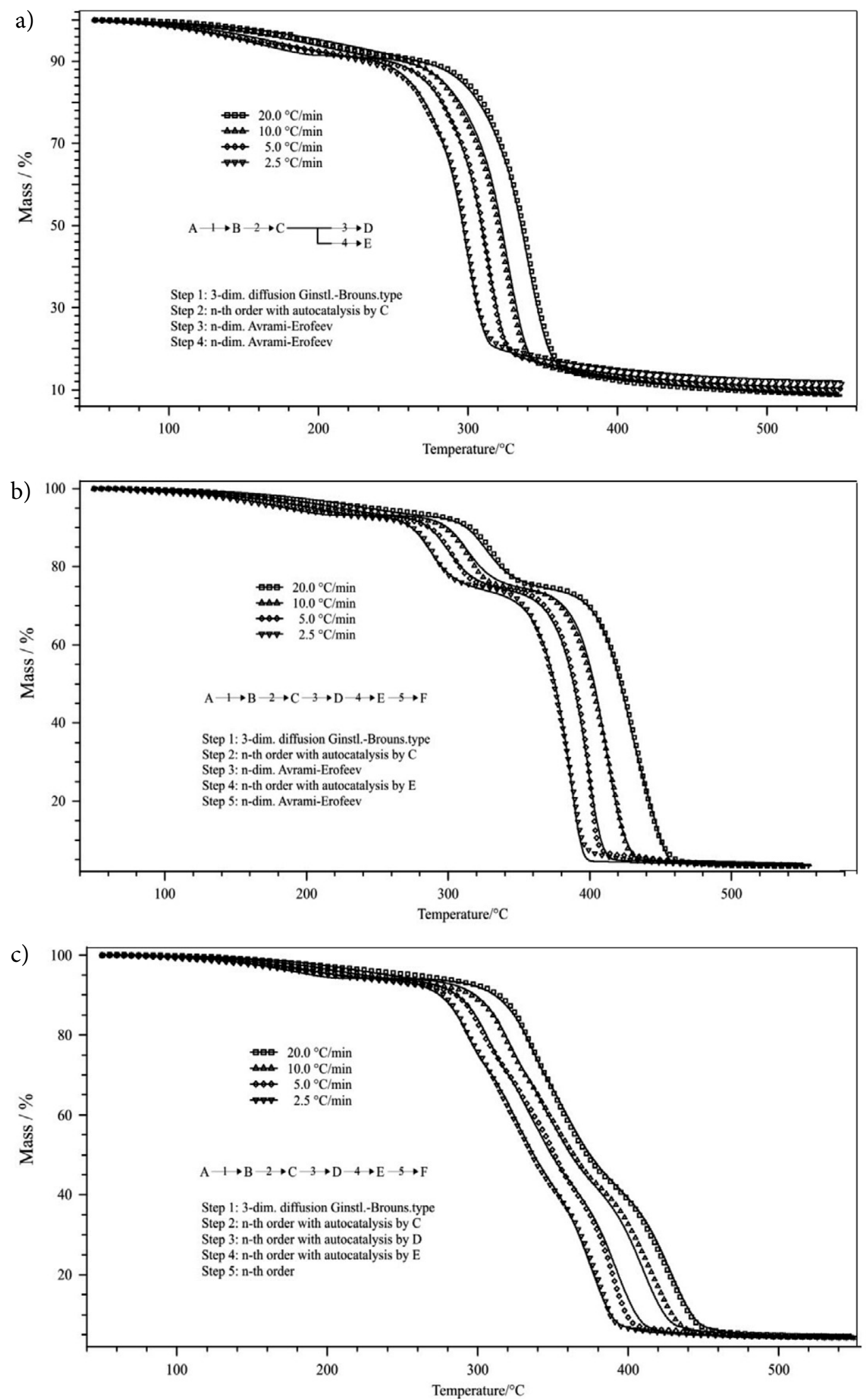

Fig. 6. Comparison of experimental data (points) and best fitted kinetic models (solid lines) calculated from multivariate nonlinear regression method for the TPS (a), PCL/TPS (b) and PCL/PLA/TPS (50/50/30) (c). 
Table 5. The most probable kinetic models of thermal degradation of PCL/TPS and PLA/TPS blends according to F-test and correlation coefficient obtained by using multivariate non-linear regression analysis

\begin{tabular}{|c|c|c|c|c|}
\hline Stage of reaction & Parameter & PCL/TPS & Sample & TPS \\
\hline \multirow{4}{*}{ Stage I } & $\mathrm{E}_{1} / \mathrm{kJmol}^{-1}$ & 64.1 & 78.1 & 56.3 \\
\hline & $\log A_{1}$ & 3.5 & 5.1 & 2.9 \\
\hline & $\mathrm{n}$ & - & - & - \\
\hline & Model & $\mathrm{D} 4$ & D4 & D4 \\
\hline Friedman & $\mathrm{kJmol}^{-1}$ & $63.9-69.0$ & $78.0-176.4$ & $48.0-107.1$ \\
\hline \multirow[t]{4}{*}{ Stage II } & $\mathrm{E}_{2} / \mathrm{kJmol}^{-1}$ & 137.0 & 155.3 & 137.5 \\
\hline & $\log \mathrm{A}_{2}$ & 9.3 & 11.3 & 9.9 \\
\hline & $\mathrm{n}$ & 2.3 & 0.6 & 0.6 \\
\hline & Model & $\mathrm{Cn}$ & $\mathrm{Cn}$ & $\mathrm{Cn}$ \\
\hline Friedman & $\mathrm{kJmol}^{-1}$ & $131.4-136.9$ & $132.1-159.1$ & $129.4-157.9$ \\
\hline \multirow[t]{4}{*}{ Stage III } & $\mathrm{E}_{3} / \mathrm{kJmol}^{-1}$ & 142.0 & 109.3 & 173.5 \\
\hline & $\log A_{3}$ & 8.7 & 6.5 & 13.0 \\
\hline & $\mathrm{n}$ & 1.8 & 0.6 & 0.1 \\
\hline & Model & An & $\mathrm{Cn}$ & An \\
\hline Friedman & $\mathrm{kJmol}^{-1}$ & $140.6-157.9$ & $92.4-121.3$ & $146.8-173.9$ \\
\hline \multirow[t]{4}{*}{ Stage IV } & $\mathrm{E}_{4} / \mathrm{kJmol}^{-1}$ & 101.0 & 147.8 & 65.4 \\
\hline & $\log \mathrm{A}_{4}$ & 5.4 & 12.5 & 1.6 \\
\hline & $\mathrm{n}$ & 0.4 & 3.1 & 0.1 \\
\hline & Model & $\mathrm{Cn}$ & Fn & An \\
\hline Friedman & $\mathrm{kJmol}^{-1}$ & $94.5-134.9$ & $146.7-291.4$ & $0.0-279.2$ \\
\hline \multirow[t]{4}{*}{ Stage V } & $\mathrm{E}_{5} / \mathrm{kJmol}^{-1}$ & 216.3 & - & - \\
\hline & $\log A_{5}$ & 14.1 & - & - \\
\hline & $\mathrm{n}$ & 5.9 & - & - \\
\hline & Model & An & - & - \\
\hline Friedman & $\mathrm{kJmol}^{-1}$ & $136.4-266.4$ & - & - \\
\hline \multicolumn{2}{|c|}{ Correlation coefficient, $\mathrm{r}^{2}$} & 0.99986 & 0.99949 & 0.99985 \\
\hline
\end{tabular}

Bna together with An and Cn models belongs to the same reaction types: accelerating one. ${ }^{42}$ Moreover, Prout-Tompkins model belong to the autocatalysis reaction type as well as $\mathrm{Cn}$ model. The final stage of thermal degradation of all PCL/PLA/TPS blends occurs by the reaction of nth order (Fn). Based on the TG analysis, PCL/PLA 30/70 blend and PCL/PLA/TPS 30/70 blend showed the worst thermal stability. These results are perfectly consistent and prove that TPS addition did not affected thermal degradation and kinetics of PCL/PLA blends at higher conversion range.

Netzsch Thermokinetics 3.1 as a software module, used for the kinetic evaluation of the thermal measurements, in this case thermogravimetry, contains the isoconversional analysis, linear regression and multi-variate nonlinear regression method with advanced statistical analysis. ${ }^{42}$ The basic principle consists of fitting a series of reaction model types ${ }^{39-42}$ to experimental data. As a mean of verification, a method of least squares and $\mathrm{F}$ test method are used. However, one need to be aware of that softwares like Netzsch Thermokinetics used in this work give advantage to the quality of fit at the expense of the physical meaning of calculated kinetic models. It is possible and can be expected to happen that the mechanism with the best fit does not represent the real degradation process. ${ }^{45}$ Hence, the apparent activation energy values obtained by isoconversional Friedman method correspond to ones calculated by a multivariate nonlinear regression method for all degradation stages confirming the fit of most probable kinetic models (Tables 4-6). The majority kinetic models can be forced to fit experimental data with a very high correlation coefficient, but only in case of true kinetic model $E$ values similar to those obtained with isoconversional methods will be obtained. Hence, this criterion of similarity with isoconversional $E$ values is crucial for selection of correct kinetic models. ${ }^{45}$

\section{Conclusions}

The main goal of this work was to provide new insights into kinetic analysis of the non-isothermal degradation of neat PCL, PLA and TPS and their investigated blends prepared by Brabender kneading chamber. For this purpose isoconversional Friedman method in combination with the multivariate nonlinear regression method, 
Table 6. The most probable kinetic models of thermal degradation of PCL/PLA/TPS blends according to F-test and correlation coefficient obtained by using multivariate non-linear regression analysis

\begin{tabular}{|c|c|c|c|c|}
\hline \multirow{2}{*}{ Stage of reaction } & \multirow{2}{*}{ Parameter } & \multicolumn{3}{|c|}{ PCL/PLA/TPS } \\
\hline & & $70 / 30 / 30$ & $50 / 50 / 30$ & $30 / 70 / 30$ \\
\hline \multirow[t]{4}{*}{ Stage I } & $\mathrm{E}_{1} / \mathrm{kJmol}^{-1}$ & 76.2 & 74.1 & 88.0 \\
\hline & $\log A_{1}$ & 5.2 & 4.8 & 6.5 \\
\hline & $\mathrm{n}$ & - & - & - \\
\hline & Model & D4 & D4 & D4 \\
\hline Friedman & $\mathrm{kJmol}^{-1}$ & $77.3-127.1$ & $74.1-140.5$ & $88.8-101.1$ \\
\hline \multirow[t]{4}{*}{ Stage II } & $\mathrm{E}_{2} / \mathrm{kJmol}^{-1}$ & 143.3 & 141.4 & 145.6 \\
\hline & $\log A_{2}$ & 10.6 & 10.2 & 10.9 \\
\hline & $\mathrm{n}$ & 1.4 & 0.6 & 1.4 \\
\hline & Model & An & $\mathrm{Cn}$ & An \\
\hline Friedman & $\mathrm{kJmol}^{-1}$ & $137.1-158.0$ & $140.8-187.8$ & $146.0-150.0$ \\
\hline \multirow[t]{4}{*}{ Stage III } & $\mathrm{E}_{3} / \mathrm{kJmol}^{-1}$ & 157.0 & 184.2 & 119.6 \\
\hline & $\log A_{3}$ & 10.7 & 13.5 & 8.5 \\
\hline & $\mathrm{n}$ & 2.0 & 1.6 & 1.5 \\
\hline & Model & $\mathrm{Cn}$ & $\mathrm{Cn}$ & Bna \\
\hline Friedman & $\mathrm{kJmol}^{-1}$ & $140.7-160.0$ & $127.2-186.6$ & $77.2-160.2$ \\
\hline \multirow[t]{4}{*}{ Stage IV } & $\mathrm{E}_{4} / \mathrm{kJmol}^{-1}$ & 135.1 & 136.8 & 139.6 \\
\hline & $\log \mathrm{A}_{4}$ & 7.9 & 8.1 & 9.6 \\
\hline & $\mathrm{n}$ & 4.4 & 0.6 & 1.4 \\
\hline & Model & An & $\mathrm{Cn}$ & An \\
\hline Friedman & $\mathrm{kJmol}^{-1}$ & $99.1-140.9$ & $116.8-138.3$ & $88.3-146.8$ \\
\hline \multirow[t]{4}{*}{ Stage V } & $\mathrm{E}_{5} / \mathrm{kJmol}^{-1}$ & 154.8 & 143.4 & 133.6 \\
\hline & $\log \mathrm{A}_{5}$ & 10.7 & 9.7 & 8.1 \\
\hline & $\mathrm{n}$ & 1.2 & 2.5 & 0.6 \\
\hline & Model & Fn & Fn & Fn \\
\hline Friedman & $\mathrm{kJmol}^{-1}$ & $110.7-290.1$ & $108.2-185.2$ & $108.0-156.0$ \\
\hline \multicolumn{2}{|c|}{ Correlation coefficient, $\mathrm{r}^{2}$} & 0.99967 & 0.99979 & 0.99922 \\
\hline
\end{tabular}

incorporated in Netzsch Thermokinetic 3.1 software, was utilized. Experimental data for kinetic computations was obtained by non-isothermal thermogravimetry in an inert atmosphere. Thermogravimetric analysis showed that thermal degradation of neat PCL sample proceed through two-stage degradation pattern, while neat PLA exhibited only single stage degradation. However, the degradation of low-cost natural TPS proceeds through three degradation stages. The addition of TPS affects the degradation of PCL and PLA and consequently their degradation starts at lower temperatures. Hence, TPS addition thermally destabilizes both, PCL and PLA, but notably the PCL sample. Likewise, binary blends are affected by TPS addition in the same manner.

Kinetic analysis was performed in a whole conversion range (0.0-1.0). Three-stage degradation mechanism, with consecutive reactions $\mathrm{A} \rightarrow \mathrm{B} \rightarrow \mathrm{C} \rightarrow \mathrm{D}$, proved to be appropiate for fitting the experimental data and the assumed kinetic models for neat PCL and PLA samples. As expected, a four-stage and five-stage degradation mechanism is seen in the case of the PCL/PLA blends. It can be summarized that $\mathrm{Cn}$ and An kinetic model proved to be the main kinetic models, while Fn occured at the end of degradation process of all investigated PCL/PLA blends. Contrary to all others samples, TPS sample showed four-stage degradation mechanisms with branching reaction. The apparent activation energy of the first stage of thermal degradation of TPS revealed diffusion character followed by $\mathrm{Cn}$ and An reaction types. On the other hand, in case of the PLA/TPS and PCL/TPS blends four-stage and five-stage degradation mechanism with consecutive reactions is seen, respectively. The diffusion is the rate controlling process at the beginning of degradation process indicating that the addition of TPS influences the thermal degradation and kinetics of PCL and PLA, respectively. However, the following stages of degradation for PCL/TPS and PLA/TPS blends can be described with either An or Cn kinetic model which is more-less consistent with the degradation mechanisms of the neat polymers. In case of investigated ternary PCL/PLA/TPS samples, obtained five-stage degradation mechanisms with consecutive reactions proved to be the best option. Once again, at the beginning of degradation the addition of TPS influences the thermal degradation and kinetics of PCL/ PLA binary blends. The following stages of degradation for PCL/PLA/TPS blends can be described with either An 
or Cn kinetic model except for the third stage of degradation of blend 30/70/30 which was described by Bna kinetic model. Similarity of activation energies calculated by model fitting multivariate nonlinear regression method with those calculated by the isoconversional Friedman method together with statistical F test and correlation coefficient confirmed the accuracy of calculated kinetic models.

\section{References}

1. B. Imre, B. Pukánszky, Eur. Polym. J. 2013, 49, 1215-33. DOI:10.1016/j.eurpolymj.2013.01.019

2. P. Fajardo, J. T. Martins, C. Fuciños, L. Pastrana, J.A. Teixeira, A. A. Vicente, J. Food. Eng. 2010, 101, 349-56.

DOI:10.1016/j.jfoodeng.2010.06.029

3. I. Simkovic, J. Carb. Pol. 2013, 95, 697-715. DOI:10.1016/j.carbpol.2013.03.040

4. J. F. Mendes, R. T. Paschoalin, V. B. Carmona, A. R. Sena Neto, A. C. P. Marques, J. M. Marconcini, L. H. C. Mattoso, E. S. Medeiros, J. E. Oliveira, J. Carb. Pol. 2016, 137, 452-58. DOI:10.1016/j.carbpol.2015.10.093

5. C. M. O. Müller, A. T. N. Pires, F. Yamashita, J. Braz. Chem. Soc. 2012, 23, 426-434.

6. R. Jayasekara, I. Harding, I. Bowater, G. B. Y. Christie, G. T. Lonergan, Polym. Test. 2004, 23, 17-27.

DOI:10.1016/S0142-9418(03)00049-7

7. L. Yu, K. Dean, L. Li, Prog. Polym. Sci. 2006, 31, 576-602. DOI:10.1016/j.progpolymsci.2006.03.002

8. K. Van de Velde, P. Kiekens, Polym. Test. 2002, 21, 433-442. DOI:10.1016/S0142-9418(01)00107-6

9. M. A. Woodruff, D. W. Hutmacher, Prog. Polym. Sci. 2010, 35 , 1217-1256. DOI:10.1016/j.progpolymsci.2010.04.002

10. L. S. Nair, C. T. Laurencin, Progr. Polym. Sci. 2007, 32, 762798. DOI:10.1016/j.progpolymsci.2007.05.017

11. K. Chavalitpanya, S. Phattanarudee, J. Egy. Pro. 2013, 34, 54248. DOI:10.1016/j.egypro.2013.06.783

12. J. W. Park, S. S. Im, S. H. Kim, Y. H. Kim, Polym. Eng. Sci. 2004, 40, 2539-2550. DOI:10.1002/pen.11384

13. U. Trommsdorff, I. Tomka, Macromolecules 1995, 28, 61386150. DOI:10.1021/ma00122a022

14. H. Li, M. A. Huneault, J. Appl. Polym. Sci. 2011, 119, 24394248. DOI:10.1002/app.32956

15. Z. Katančić, I. Grčić, Z. Hrnjak-Murgić, Croat. Chem. Acta. 2017, 90, 401-411. DOI:10.5562/cca3110

16. Z. Katančić, J. Travaš-Sejdić, Z. Hrnjak-Murgić, J. Jelenčić, J. Elast. Plast. 2014, 46, 233-252.

DOI:10.1177/0095244312465301

17. D. Y. Wang, U. Gohs, N. J. Kang, A. Leuteritz, R. Boldt, U. Wagenknecht, G. Hinrich, Langmuir 2012, 28, 12601-12608. DOI:10.1021/la3025099

18. O. Persenaire, M. Alexandre, P. Degée, P. Dubois, Biomacromolecules 2001, 2, 288-294. DOI:10.1021/bm0056310

19. G. Sivalingam, G. Madras, Polym. Degrad. Stab. 2003, 80, 11-16. DOI:10.1016/S0141-3910(02)00376-2
20. Y. Aoyagia, K. Yamashita, Y. Doi, Polym. Degrad. Stab. 2002, 76, 53-59. DOI:10.1016/S0141-3910(01)00265-8

21. M. Hakkarainen, Advan. Polym. Sci. 2002, 157, 113-138. DOI:10.1007/3-540-45734-8_4

22. K. G. L. Ho, A. L. Pometto, P. N. Hinz, J. Environ. Polym. Degrad. 1999, 83, 83-92.

23. J. D. Badía, L. Santonja-Blasco, R. Moriana, A. Ribes-Greus, Polym. Degrad. Stab. 2010, 95, 2192-2199.

DOI:10.1016/j.polymdegradstab.2010.06.002

24. I. C. McNeill, H. A. Leiper, Polym. Degrad. Stab. 1985, 11, 309-326. DOI:10.1016/0141-3910(85)90035-7

25. B. Janković, Carbohydr. Polym. 2013, 95, 621-629.

DOI:10.1016/j.carbpol.2013.03.038

26. N. E. Wahyuningtiyas, H. Suryanto, E. Rudiyanto, S. Sukarni, P. Puspitasari, JMES 2017, 1, 69-77. DOI:10.17977/um016v1i22017p069

27. M. P. Guarás, V. A. Alvarez, L. N. Ludueña, J. Polym. Res. 2015, 22, 165. DOI:10.1007/s10965-015-0817-0

28. V. B. Carmona, A. C. Correa, L. H. Marconcini, C. Mattoso, J. Polym. Environ. 2015, 23, 83-89.

DOI:10.1007/s10924-014-0666-7

29. J. Su, L. Chen, L. Li, Afr. J. Biotechnol. 2012, 11, 694-701. DOI:10.5897/AJB12.979

30. T. Ke, X. Sun, Cereal. Chem. 2000, 77, 761-768. DOI:10.1094/CCHEM.2000.77.6.761

31. B.Y. Shin, S. H. Jang, B. S. Kim, Polym. Degrad. Stab. 2011, 51, 826-834. DOI:10.1002/pen.21896

32. P. Sarazin, G. Li, W. J. Orts, B. D. Favis, Polymer 2008, 49, 599-609. DOI:10.1016/j.polymer.2007.11.029

33. H. L. Friedman, J. Polym. Sci. C 1963, 6, 183-195. DOI:10.1001/jama.1963.03700110135108

34. Đ. Ačkar, J. Babić, D. Šubarić, M. Kopjar, B. Miličević, Carbohydr. Polym. 2010, 81, 76-82.

DOI:10.1016/j.carbpol.2010.01.058

35. S. Vyazovkin, A.I. Lesnikovich, Thermochim. Acta. 1990, 165 , 273-280. DOI:10.1016/0040-6031(90)80227-P

36. S. Vyazovkin, N. Sbirrazzuoli, Macromol. Rapid. Commun. 2006, 27, 1515-1532. DOI:10.1002/marc.200600404

37. S. Vyazovkin, A.K. Burnham, J. M. Criado, L. A. Pérez-Maqueda, C. Popescu, N. Sbirrazzuoli, Thermochim. Acta. 2011, 520, 1-19. DOI:10.1016/j.tca.2011.03.034

38. S. Vyazovkin, K. Chrissafis, M. L. Di Lorenzo, N. Koga, M. Pijolat, B. Roduit, N. Sbirrazzuoli, J.J. Suñol, Thermochim. Acta. 2014, 590, 1-23. DOI:10.1016/j.tca.2014.05.036

39. M. Jakić, N. Stipanleov Vrandečić, M. Erceg, J. Therm. Anal. Calorim. 2016, 123, 1513-1522.

DOI:10.1007/s10973-015-5096-9

40. M. Jakić, N. Stipanleov Vrandečić, M. Erceg, J. Therm. Anal. Calorim. 2017, 127, 663-674.

DOI:10.1007/s10973-016-5768-0

41. M. Jakić, N. Stipanleov Vrandečić, M. Erceg, Eur. Polym. J. 2016, 81, 376-385. DOI:10.1016/j.eurpolymj.2016.06.024

42. NETZSCH Thermokinetics 3.1, Netzsch-Geraeteban GbmH, Software Manual.

43. N. M. N. Radhakrishnan, G. V. Thomas, N. M. R. Gopinathan, Polym. Degrad. Stab. 2007, 92, 189-196. 
DOI:10.1016/j.polymdegradstab.2006.11.014

44. L. Byczynski, Thermochim. Acta. 2014, 592, 58-66.

DOI:10.1016/j.tca.2014.08.018

45. M. Erceg, I. Krešić, M. Jakić, B. Andričić, J. Therm. Anal. Calorim. 2017, 127, 789-797. DOI:10.1007/s10973-016-5413-y

\section{Povzetek}

$\mathrm{Z}$ uporabe neizotermične termogravimetrije $\mathrm{v}$ inertni atmosferi smo preučevali termično stabilnost poli(e-kaprolaktona) (PCL), polilaktične kisline (PLA), termoplastičnega škroba (TPS) in njihovih binarnih (PCL/PLA, PCL/TPS and PLA/ TPS) ter ternarnih (PCL/PLA/TPS) mešanic. Vse preučevane mešanice smo pripravili z Brabender mešalnikom. PCL izkazuje dvostopenjsko termično razgradnjo, medtem ko je razgradnja PLA le enostopenjska. Po drugi strani pa poteka razgradnja samega TPS v treh stopnjah. Izkazalo se je, da dodatek PLA vpliva na razgradnjo PCL/PLA mešanic, kar kaže, da PLA destabilizira PCL. Dodatek TPS prav tako destabilizira oba, PCL in PLA, a še posebej PCL. Prav tako dodatek TPS destabilizira vse ternarne mešanice. $Z$ uporabo izokonverzijske Friedman-ove metode in multivariante nelinearne regresije smo analizirali kinetiko. Analiza je pokazala kompleksnost termične razgradnje procesa posameznih polimerov pa tudi njihovih mešanic. Izračunali smo kinetične parametre (aktivacijsko energijo, predeksponentni faktor in kinetični model) vsake faze razgradnje za posamezne polimere in njihove mešanice.

Except when otherwise noted, articles in this journal are published under the terms and conditions of the Creative Commons Attribution 4.0 International License 